Hermine Penz*

\title{
Communicating climate change: how (not) to touch a cord with people and promote action
}

https://doi.org/10.1515/text-2020-0081

Received May 8, 2020; accepted January 18, 2022; published online February 2, 2022

Abstract: Climate science has established human activity as the major cause of climate change. The successive reports of the Intergovernmental Panel on Climate Change (IPCC) have also provided future scenarios of the detrimental effect of rising temperatures. Despite the overwhelming scientific consensus, the voices of climate deniers are still given ample space in the media. Moreover, the urgency of the problem and the importance of taking action are difficult to communicate to the public. This paper analyses the communication strategies employed by climate scientists, climate deniers and climate activists to identify similarities and differences, in particular with regard to expressing (un)certainty. The data are media reports from major British and US newspapers, IPCC reports and the speeches of climate activists, in particular Greta Thunberg. The data are analysed by means of qualitative (eco)critical discourse analysis. The aim is to draw conclusions about how climate change could be communicated more effectively to the general public to promote action.

Keywords: climate action; climate change; communication; eco-critical discourse analysis; IPCC; (un)certainty

\section{Introduction}

Climate change has become one of the most pervasive issues of our time and has been hotly debated among various audiences. Human activity has been established as the major cause of climate change, which means that there is widespread scientific consensus on the anthropogenic character of this phenomenon. The successive reports of the Intergovernmental Panel on Climate Change (IPCC) have also provided future scenarios of the detrimental effect of rising temperatures.

*Corresponding author: Hermine Penz, Institut für Anglistik/Department of English Studies, KarlFranzens-Universität Graz/University of Graz, Heinrichstrasse 36, A-8010 Graz, Austria, E-mail: hermine.penz@uni-graz.at 
Despite a 97\% agreement among climate scientists (see National Aeronautics and Space Administration [NASA 2020]), the voices of climate deniers are still given ample space in the media. Moreover, the urgency of the problem and the importance of taking action are difficult to communicate to politicians and the public.

Despite the ubiquity of climate change, communicating its consequences to different audiences has turned out to be a difficult undertaking. A particularly problematic aspect has been the issue of uncertainty. This relates both to the findings of climate science and the question of how uncertainty is communicated to various audiences. For over two decades, uncertainty was related to the question of whether climate change is anthropogenic (i.e. caused by humans) or not (see Nerlich et al. 2010). The majority of research has been concerned with media representations of climate change in connection with this issue. It has been demonstrated that in the US, media representations have tended to portray the results of climate science with a higher degree of uncertainty than scientific consensus would allow (Boykoff 2007).

This paper investigates the question of how different actors express uncertainty in relation to anthropogenic climate change. After providing a brief overview of climate science, the language of (un)certainty in the fifth Assessment Report of the IPCC (2014) regarding human responsibility for climate change is discussed. This is followed by an examination of the representation of the IPCC findings in US and UK media. The analysis then turns to a webpage created by climate change deniers to identify the arguments (regarding (un)certainty) and the linguistic strategies employed by this group. Finally, some of Greta Thunberg's rhetoric will be analysed with respect to the communication of (un)certainty. The findings of these analyses will then be discussed in relation to attempts at more effective ways of communicating and engaging the public.

\section{Literature review}

\subsection{Communicating climate change}

The study of communication about climate change goes hand in hand with the increasing prominence of this issue in the public sphere. The topic has been dealt with in the larger context of environmental communication (see Cox 2006), yet due to myriad publications, it has even been argued that climate change communication can be considered a field of its own (Nerlich et al. 2010). According to Nerlich et al. (2010), this field discusses the importance and difficulties inherent in talking about climate change to different types of audience, deals with the relationship between climate change communication and behavior change, and the role of 
language. Different actors and different target groups are necessarily involved in communicating climate change, among them scientists, politicians, industries, activists, and the general public.

\subsection{Climate science and the IPCC reports}

The Intergovernmental Panel on Climate Change (IPCC) of the United Nations has published regular reports based on the available scientific evidence on climate change. The IPCC gathers all the scientific data available, reviews it and draws conclusions about the current science on climate change. Thousands of scientists worldwide are involved in the work of the IPCC. Governments of 195 member states participate in the reviewing process and approve the final versions, in particular the Summary Reports for Policy Makers. Since its foundation in 1988, the IPCC has published five assessment reports, the last of which appeared in November 2014 (see www.ipcc.ch). The next (6th) Assessment Report is scheduled to appear in 2022. Since the first IPCC report published in 1990, human influence on climate change has been established as an important factor. In each successive report, the degree of certainty relating to the anthropogenic causes has increased. The IPCC reports have also provided future scenarios of the detrimental effect of rising temperatures. Recently, a Special Report has been published on the impacts of global warming of $1.5^{\circ} \mathrm{C}$ in comparison with a $2^{\circ}$ increase above pre-industrial levels to illustrate the importance of increasing global action (IPCC 2018).

\subsection{Media communication of climate change}

The mass media serve as the main source of information on climate for the general public. They play an important role in translating science and mediating between scientists and policy makers (Nerlich et al. 2010: 99). The media constitute the main source of information on scientific knowledge for lay people and influence people's understanding of issues such as climate change (Boykoff 2008: 550). This is why the study of media representations forms a crucial component of climate change communication. Research on climate change discourse in the media has investigated a number of different domains such as the analysis of media reporting related to the publication of IPCC reports, climate change conferences and related events, and reports on natural disasters as a consequence of climate change (see Schäfer and Schlichting 2014). More recently, actions in connection with the Fridays for Future movement, which was initiated by Greta Thunberg's climate strike, have become a prominent media focus. 
A large amount of research concerned with media communication on climate change has centered on how climate change is framed. According to Entman (1993: 52) framing means to "select some aspects of a perceived reality and make them more salient in a communication text". Frames are cognitive and cultural models which help us structure our knowledge and understanding. They are triggered by particular words or metaphors, and by prompting particular interpretations of word meanings they can account for multiple understandings of the same situation (see Kövesces 2006; Lakoff 2010). In the extant literature on framing in climate change a number of different frames have been proposed by researchers (e.g. Bolsen and Shapiro 2018; Penz 2018). Among the frames that have been identified the following hold a dominant position: a) Certainty/uncertainty, b) Risks (extreme weather events/natural catastrophes) or uncertainty, c) Business and economics, d) Climate security (addressing threats of conflict/war and food and water security), and e) Mitigation (of climate change and its effects). With regard to the frame of (un)certainty it has been revealed that, despite scientific consensus that climate change is largely caused by human activity, media reporting has portrayed the anthropogenic nature of it as an issue of uncertainty and debate. Boykoff (2007), for example, has demonstrated that in US media, the norm of 'balanced reporting' has given more space to the voices of climate skeptics than scientific consensus would justify.

Studies of media reports in different countries in the early 21st century have identified differences between individual countries regarding uncertainty in media representations about scientific findings (see Painter and Gavin 2016). A study by Collins and Nerlich (2016) has demonstrated that uncertainty has been understood differently at different times in UK media reporting. While it was employed to question climate science after the 'Climategate' affair' and the failure of the Copenhagen accord, uncertainty was rather discussed in connection with climate mitigation activities after the publication of the 5th IPCC report and the Paris summit in 2015. Although human action has now been established as the main contributing factor to climate change by successive IPCC reports, uncertainty still plays a role in other details of climate science (see Schäfer \& Schlichting 2014: 143).

Studies of media reporting on climate change have also revealed diverging results on the impact on the audience. Some researchers have argued that the content and wording are less important than the amount of reporting (Mazur and Lee 1993, quoted in Kuha 2009), while others assert that the content of media

1 Before the climate summit in Copenhagen 2009, emails between climate scientists from the University of East Anglia were hacked and made public. Since there seemed to be some evidence that data had been hidden und critical voices suppressed, climate science lost credibility due to this incident (see Collins and Nerlich 2016: 294). 
coverage does have an impact. Kuha (2009: 3) concludes that the attention which media consumers pay seems to be a crucial factor: When media consumers are attentive to news coverage, they will focus on the content, yet when they are not, the amount (my emphasis) of coverage plays a more important role.

\subsection{Expressing (un)certainty in language}

When communicating about any issue, this can be accomplished with different degrees of certainty. The spectrum of facticity can be expressed by linguistic modality expressions which can range from extremely high to very low uncertainty (see Stibbe 2015: 130). Since scientists consider their work an ongoing process of contributing to knowledge, conventions demand that findings should be formulated with caution rather than as categorical assertions or facts. Hedges, i.e. linguistic devices which signal uncertainty, are therefore used quite frequently in science communication (Hyland 2006). Other strategies include referring to evidence from experts and the consensus of authorities (see van Leeuwen 2008: 107). Certainty is frequently expressed by assertions in indicative mood, which may be reinforced by emphasis (real, unmistakable, etc.) or evidential information (e.g. 'as studies have demonstrated'). However, certainty may take the form of presupposition, i.e. underlying (implicit) assumptions whose truth is taken for granted (see Labinaz and Sbisà 2014: 44-47). Additional ways of expressing facticity mentioned by Stibbe (2015: 130) are: Quantifiers which can hide the lack of concrete evidence (e.g. 'some or 'any'), and verbal hedges which reduce the facticity of others' views (e.g. 'X thinks' or 'X believes') (based on Machin and Mayr 2012: 189).

Kuha's (2009: 4-6) categorization of (un)certainty expressions comprises reporting verbs (signaling the degree of commitment that a speaker or writer makes to the truth of a statement), as well as propositions introduced by factive verbs (highest degree of certainty) and non-factive verbs, which range from expressing some certainty ('predict') to less certainty ('believe', 'suggest'), including propositions modified by the modal verbs 'could', 'may', and 'might'.

\subsection{Communicating uncertainties to various audiences}

One crucial aspect of climate change communication centres around the issue of uncertainty. On the one hand, this relates to the complexity of uncertainties connected to the science of climate change; on the other, it relates to how uncertainty is communicated and understood by various audiences. Defining uncertainty is not as easy as one might think. Uncertainty frequently refers to an absence 
of knowledge. However, this is not a question of 'either-or' as certainty can be viewed as a dimension which can range from absolute certainty to complete ignorance. Indeed, it can even be seen as one of the degrees along this scale. ${ }^{2}$ One way of expressing uncertainty is in terms of probability (numerical uncertainty). Probabilities range on a spectrum from highly unlikely to extremely unlikely; they are future likelihoods (based on hypotheses). Unlike probabilities, likelihood has no meaning per se, but only becomes meaningful when comparing likelihoods (see Etz 2018).

In science communication, uncertainty has frequently been concerned with closing knowledge gaps; this means creating more knowledge about climate change and reducing uncertainties. This is also reflected in the way gaps in knowledge have been dealt with in successive IPCC reports (see Hulme 2018). While in the first report (FAR) in 1990, the IPCC saw the reduction of uncertainties with respect to predicting the Earth's climate system as their priority, in their third report (TAR) in 2001 the IPCC attempted to close knowledge gaps by expanding the knowledge base into different areas and applying an increased repertoire of methodologies. The fourth assessment report (AR4), published in 2007, identified eight key areas of uncertainties, for example the speed at which the polar ice caps will melt (see Hulme 2018).

Scientific research is frequently faced with the problem of expressing uncertainty. ${ }^{3}$ Environmental sciences, in particular, are confronted with the problem that absolute certainty can hardly ever be established in relation to large-scale problems such as climate change. Many people are unaware that there is a substantial difference between public understanding of uncertainty and scientists' views. While the public may interpret uncertainty as a (relative) lack of knowledge or even ignorance, scientists deal with uncertainty as their everyday business, which may even lead to interesting questions (see Painter 2013: 7). Due to their perception of uncertainty the general public will not demand action (or be willing to act) if uncertainty about an issue exists. People's interpretation of uncertainty also seems to be connected to distance: They behave as if uncertainties which are closer to them (in time and space) are more certain than those which are further away (see Rachlin 1989, in Smithson 2009: 16). Depending on these perceptions, individuals may not act, nor will political action take place or only at a low level/ half-heartedly. On the basis of this assumption, various communication strategies

2 I would like to thank an anonymous reviewer for pointing out the different ways of interpreting uncertainty.

3 Risk is frequently connected to uncertainty as well. It can be considered as one category of uncertainty. According to van der Heijden (1996), a defining feature of risk is that "likelihood can be assessed and outcomes or impacts can be estimated" (Delaney 2009: 142). 
have been employed by industry to challenge scientific findings and cast doubt on their validity and seriousness (Painter 2013).

The Intergovernmental Panel on Climate Change (IPCC) has made great efforts to communicate the uncertainties connected with the scientific knowledge about climate change since the early days of reporting on the topic. The 5th IPCC report, for example, states that it is 'extremely likely' that the major causes of climate change are human made. The degree of likelihood has been calculated as between 95 and $100 \%$. Whereas in other spheres of life such a high percentage would probably be communicated as a proven fact, scientists aim at presenting their findings as accurately as possible.

While one possibility lies in the documentation of numerical probabilities, it is often felt that these should be translated into more everyday conceptions of uncertainty if research results are (or need to be) communicated to the general public (see also Sarangi 2002 on communicating likelihood in genetic-counselling discourse). This problem has been very explicitly addressed by the IPCC. The reports provide translations of numerical probabilities into standardized expressions of uncertainty. The same standardised linguistic expressions are applied in the Special Report 2018.

Elaborate guidelines were provided for the consistent treatment of uncertainties to the lead authors of the fifth assessment report (AR5) (see Mastrandrea et al. 2010). A scale of certainty was developed for an outcome based on degrees of likelihood and confidence which are related to the quantitative approaches used: virtually certain 99-100\% probability, very likely $90-100 \%$, likely 66-100\%, about as likely as not 33-66\%, unlikely 0-33\%, very unlikely $0-10 \%$, exceptionally unlikely 0-1\%. Additional terms include extremely likely 95-100\%, more likely than not $>50-100 \%$, more unlikely than likely $0-<50 \%$, and extremely unlikely $0-5 \%$. In addition, levels of confidence for expert judgments on the correctness of scientific results are indicated in the following way: very low, low, medium, high and very high, and typeset in italics, e.g., medium confidence (SYR of AR5 2014: 1).

A few studies have investigated how (un)certainty is expressed through language in the field of climate change. Fløttum (2010: 2) points to the importance of studying how climate knowledge originating in scientific discourse is translated to different actors and how it is discursively constructed. Among other features, she has analysed knowledge claims and epistemic modifiers in the 4th IPCC summary report of 2007. Kuha (2009) has focused on expressions of certainty in connection with the effects of global warming in US news coverage.

In their study of how scientific uncertainty in the IPCC reports of 2001 and 2007 was translated into US and Spanish national newspapers, Bailey et al. (2014) investigated qualifying and hedging language and other 'epistemic markers'. They 
found that despite growing scientific consensus, hedging language/epistemic marking did not decrease. Both Spanish and US newspapers used similar words when questioning the certainty of climate change, yet the US newspapers used a higher number of epistemic markers as well as epistemic markers with a negative tone (e.g. hoax, controversy). Spanish newspapers more frequently expressed scientific uncertainties using numerical ranges and conditional clauses, while US newspapers used more noun phrases and adjectives "to construct uncertainty around climate change” (p. 212). It has been demonstrated by Harris et al. (2013) that the IPCC reports are interpreted differently by different people, depending on the types of events described and one's cultural background. In addition, it has been shown that the interpretation of English speakers frequently does not coincide with the probabilities which the authors of the IPCC reports had in mind. Another problem is that the communication of uncertainty tends to prevent action: The communication of uncertainties and doubt provides climate sceptics with fuel for their arguments, and human beings' daily experiences and political convictions are far more likely to influence their actions than any statistics and reports produced by researchers (Corner et al. 2018; Klein 2014).

Despite the value of the guidelines for communicating climate change issued by the IPCC, Carvalho et al.'s (2017) criticism that most citizens feel disconnected from the debate and decision-making should still be taken into consideration. They point out that climate change discourse can be characterised by "depolitisation", which is a process by which "people are pushed into the role of passive spectators rather than active participants" (p. 128). In a similar vein, Nerlich et al. (2010: 106) have criticized the fact that research on public engagement with climate change has been dominated by "a limited view of the relationships between science and society, a limited view of the public and a curiously truncated view also of communications research as being about finding the right words and checking if people have listened". They claim that climate change communication should aim at meaningful engagement which includes understanding, emotion and behavior (p. 100).

As has been argued above, communication should be seen as an active exchange of views and provide space for participation if citizen engagement is to be encouraged. This includes providing participatory political spaces that allow people to express their views and act. One reason why Greta Thunberg's "Fridays for Future" movement has been so successful is probably the fact that it has activated the youth around the world and opened up a space of action for them. 


\section{Data and methodology}

The analysis of expressing (un)certainty regarding the anthropogenic nature of climate change first focuses on a passage from the IPCC report and its media translations in three UK papers (The Guardian [G], The Observer [O], The Daily Telegraph [DT]) and three US newspapers (The New York Times [NYT], USA Today [UT], The Wall Street Journal [WSJ]). Two articles were selected from each, published between 19th August and 1st October 2013, relating to the publication of the 5th IPCC report. A brief glimpse of how climate (un)certainty is dealt with by climate change deniers is provided by a text extract by Nigel Lawson in The Daily Telegraph and the website of the Nongovernmental International Panel on Climate Change (NIPCC), which is hosted by the Heartland Institute, an organisation heavily funded by the oil and tobacco industries. Finally, (un)certainty is investigated in extracts from Greta Thunberg's speech to the World Economic Forum in Davos, 2019.

The linguistic expression of uncertainty will be the focus of the analysis in this paper. My approach can be placed within eco-critical discourse analysis as it attempts a critical analysis of environmental discourses. Eco-critical discourse analysis is one of several strands within the field of ecolinguistics which takes an ecological approach to language and emphasizes the interrelatedness of language and its social, cognitive and natural environments (see Alexander 2009; Döring 2018; Fill 1993; see also Stibbe 2014 and 2015 as well as Steffensen and Fill 2014). Eco-critical discourse analysis has not developed specific methodologies but applies analytic procedures developed in linguistic (text and discourse) analysis (see Döring 2018). The analysis of climate change discourse in this paper aims at investigating the linguistic realization of uncertainty in the discourses of different actors.

\section{Findings}

\subsection{Communication of uncertainty in IPCC reports and media representations}

In the IPCC reports verbal expressions are used to replace numerical values. In her analysis of AR4, Fløttum argues that "they use a scientifically-based system of calibrated expressions, epistemic modifiers, which are clearly defined” (2010: 12). This system is apparently based on the assumption that the (un)certainties expressed are more accessible to political representatives and the general public in 
their verbalised version. The fifth IPPC report has established very clearly that climate change is anthropogenic to a high degree. The certainty relating to human influence will be the focus of the analysis of extracts from AR5 and media representations of this issue.

The following text extracts from the Synthesis Report for Policy Makers (SYR of AR5, 2014) illustrate the use of verbalised expressions of likelihood: ${ }^{4}$

SPM 1. Observed Changes and their Causes

Human influence on the climate system is clear, and recent anthropogenic emissions of greenhouse gases are the highest in history. Recent climate changes have had widespread impacts on human and natural systems. $\{\mathbf{1}\}$

SPM 1.1 Observed changes in the climate system

Warming of the climate system is unequivocal, and since the 1950s, many of the observed changes are unprecedented over decades to millennia. The atmosphere and ocean have warmed, the amounts of snow and ice have diminished, and sea level has risen. $\{1.1\}$

Human influence has been detected in warming of the atmosphere and the ocean, in changes in the global water cycle, in reductions in snow and ice, in global mean sea level rise, and in changes in some climate extremes (see Figure SPM6. and Table SPM.1). This evidence for human influence has grown since AR4. It is 'extremely likely' that human influence has been the dominant cause of the observed warming since the mid-20th century. (p. 47) [passages in bold my emphasis]

At the beginning of this extract, the IPCC clearly establishes human influence as the dominant cause of climate change by an unmodified assertion. Similarly, the warming of the atmosphere is stated as unequivocal. The last paragraph provides scientific evidence for the growing human influence and continues by stating the likelihood of human action being the dominant cause as 'extremely likely', but it does not include a numerical value. The scales of likelihood which include the respective percentages are only provided in footnote $\{1\}$ of the report (see scale in Section 2.5).

When the IPCC reports get 'translated' for the general public by the media, it is interesting to observe the extent to which the language of this report is actually used with regard to the (un)certainty expressed by the IPCC. It is also interesting whether the newspapers provide a correct understanding of the text of the report,

4 Verbalised expressions of likelihood are italicised throughout the IPCC Report. As examples from data are presented in italics throughout this article, single inverted commas are used for highlighting the original italics. 
i.e., what the IPCC is certain about (that human influence is one of the causes) and what they are still uncertain about (that human contribution is the dominant cause). For this purpose, major UK and US newspapers were examined when the fifth IPCC report (or an unauthorised version that was leaked beforehand) was published in September 2013. The table below demonstrates the ways the certainty relating to human responsibility for climate change was reported.

What is striking about these examples is that both UK and US newspapers show a strong preference for numerical values of certainty over the verbal terms used in the report. Despite strong efforts on the part of the IPCC to use verbal expressions for (un)certainty these are not adopted, probably because they appear more vague than numerical values.

Most newspaper reports reflect the high degree of certainty about the anthropogenic origin of climate change and convey the urgency of the findings. The passage from The Independent below even uses a comparison relating to the certainty of cigarettes causing cancer and points to the source, i.e. hundreds of scientists.

"The fifth IPCC report may not contain much that is absolutely new. What has changed, though, since 2007, is the degree of certainty. It is now as sure that human beings are causing climate change - 95 per cent - as that cigarettes cause cancer. This is not the judgement of politicians or campaigners; it is the consensus of hundreds of scientists, from all over the world, having considered all available evidence.” (The Independent, UK, 27 Sept. 2013).

An extremely high level of facticity is expressed in the other text extract from The Independent (from 26 Sept.), which even contains a booster in "Our environment is incontestably warming" and asserts that "it is beyond reasonable doubt that human activities are the cause".

Out of the 12 news articles analysed, only two reflected climate scepticism or denialism. These do not consider human activity as the main contributing factor to climate change. The text in extract i) of Table 1 even casts doubt on the established fact of global warning and does not question the cause. In the next section an extended version of extract e) from Table 1, which represents the perspective of deniers, will be discussed in more detail (see example (3)).

\subsection{Communication strategies of climate change deniers}

Climate change deniers systematically aim to discredit the findings published in the IPCC reports. As previously mentioned, despite the overwhelming evidence for anthropogenic climate change, news reporting has tended to give ample space to 
Table 1: Expressions of likelihood regarding anthropogenic climate change in selected UK and US newspapers.

\section{Text extract}

Newspaper

a) ... scientists have revised upwards the certainty that human activities are driving

the warming the world has experienced, from "very likely" or $\mathbf{9 0 \%}$ confidence in $26 \mathrm{Sept}$.

2007 , to "extremely likely" or $95 \%$ confidence now

b) ... also found it was 'unequivocal' that global warming was happening as a result UK, G of human actions

27 Sept.

c) Our environment is incontestably warming - each of the past three decades has been successively warmer than any since 1850 - and it is beyond reasonable doubt 26 Sept. that human activities are the cause.

d) What has changed, though, since 2007, is the degree of certainty. It is now as sure UK, I that human beings are causing climate change $\mathbf{- 9 5}$ per cent - as that cigarettes 27 Sept. cause cancer. This is not the judgement of politicians or campaigners; it is the consensus of hundreds of scientists, from all over the world, having considered all the available evidence. One can only hope that it will banish the scepticism of the ignorant ...

e) On Friday, the UN published its landmark report into climate change, which claimed with "95 per cent" certainty that global warming is man-made. ...

...whereas in $\mathbf{2 0 0 7}$ it was $\mathbf{9 0}$ per cent sure that most of the (very slight) global warming recorded since the Fifties was due to man-made carbon emissions, it is now 95 per cent sure.

This is not science: it is mumbo-jumbo. Neither the $\mathbf{9 0}$ per cent nor the 95 per cent have any objective scientific basis [denialist]

e) An international panel of scientists has found with near certainty that human activity is the cause of most of the temperature increases...

... the odds are at least 95 percent that humans are the principal cause

f) the report said. "It is extremely likely that human influence has been the dominant cause of the observed warming since the mid-20th century".

US, NYT

g) ... there's $95 \%$ certainty that man-made global warming is real. A 2007 IPCC

27 Aug report put the confidence level at about $\mathbf{9 0 \%}$.

US, UT

h) A summary of the report ... said there is a $\mathbf{9 5 \%}$ likelihood that humans are behind

24 Sept. global warming, up from the $\mathbf{9 0 \%}$ level of certainty in a similar 2007 report

i) "Warming of the climate system is unequivocal," insists the report in its first boldUS, WSJ face conclusion, followed by the claim that "each of the last three decades has been successively warmer at the Earth's surface than any preceding decade since 1850." 27 Sept. US, WSJ 1 Oct. ... So what about the warming that hasn't been happening since 1998? [denialist]

the voice of climate critics, such as Nigel Lawson, a former UK politician, whose views have featured very prominently in conservative newspapers, as in the following extract from The Daily Telegraph: 
(3) The true scientific method is founded on empirical observation. When a theory - whether embedded in a computer program or not - produces predictions that are falsified by subsequent observation, then the theory, and the computer models which enshrine it, have to be rethought.

Not for the IPCC, however, which has sought to obscure this fundamental issue by claiming that, whereas in 2007 it was 90 per cent sure that most of the (very slight) global warming recorded since the Fifties was due to manmade carbon emissions, it is now 95 per cent sure.

This is not science: it is mumbo-jumbo. Neither the 90 per cent nor the 95 per cent have any objective scientific basis: they are simply numbers plucked from the air for the benefit of credulous politicians and journalists. (The Daily Telegraph, 28 Sept. 2013)

This extract illustrates the argumentation strategies of the UK climate change denier Nigel Lawson. The methods of climate scientists are attacked by accusing them of not being able to support their predictions by observation, an accusation that is based on wrong assumptions about computer modelling and prediction of long-term scenarios. While the first part of the text applies the language of science, it then changes to everyday language use by translating certainty into 'being sure'. The text closes by denying the findings' scientific status and debasing them as 'mumbo-jumbo'.

In the US, deniers have campaigned heavily against climate change and have also received extensive media coverage despite the overwhelming scientific consensus. Among the most active campaigners against climate change is the Heartland Institute, which is heavily funded by the tobacco and oil industry (see Klein 2014, see also Wikipedia). They even organize climate change conferences and have set up the NIPCC, which aims to counteract the scientific consensus that climate change is human made. It is modelled on the IPCC and claims to provide 'alternative' scientific views on climate change ( $3 \%$ of scientists). The following extract illustrates how they present themselves on the NIPCC website (NIPCC 2020):

The Nongovernmental International Panel on Climate Change (NIPCC) is an international panel of nongovernment scientists and scholars who have come together to present a comprehensive, authoritative, and realistic assessment of the science and economics of global warming. Because it is not a government agency, and because its members are not predisposed to believe climate change is caused by human greenhouse gas emissions, NIPCC is able to offer an independent "second opinion" of the evidence reviewed or not reviewed - by the Intergovernmental Panel on Climate Change (IPCC) on the issue of global warming 
As mentioned above, the NIPCC appropriates the language and structure of the IPCC to spread views which deny human influence on climate change. It attempts to suggest controversy concerning climate change (despite $97 \%$ agreement), discrediting the IPCC. Stressing its non-governmental character, it establishes itself as authoritative and realistic in contrast to the government agencies, whose members (who include thousands of climate scientists) are denigrated and accused of being 'predisposed to believe' that climate change is caused by human emissions. This is a charge which includes very strong bias, even insinuating that the claims of scientists are influenced by political manipulation and personal interest. This accusation against the IPCC is formulated with respect to expressions of uncertainty, in particular, in the following extract:

(5) Numerous authors (see here, here, and here) $<3>$ have observed a growing disconnect between the "Summaries for Policymakers," which are designed to be read and used by political leaders and the media, and the reports themselves. The former systematically remove the expressions of scientific uncertainty and alternative explanations of climate phenomena [my emphasis] that were abundantly present in the first three reports, with the obvious intention of misrepresenting the science and fueling unnecessary alarm.(http://climatechangereconsidered.org/about-theipcc/)

In extract (5) the NIPCC attempts to present the summary version of the IPCC report as a form of deception, accusing the IPCC of misrepresenting science, in particular by removing the expressions of scientific uncertainty, thus causing unnecessary alarm.

The analysis of these short extracts is in line with the findings of Stibbe (2015), who argues that climate change deniers present themselves as scientists and specialists who are disinterested observers, in contrast to climate change advocates who are accused of having a political agenda. It has also been stated frequently that the experts that deniers refer to do not usually have expertise in climate science but in other areas (Boykoff 2007; Klein 2014). In the examples above, the deniers state with full certainty that the climate scientists are wrong, while they themselves provide an objective second opinion. Deniers' strategy of casting doubt on scientific results and the degree of consensus among scientists has also been observed in previous research (see Boykoff 2007).

According to Klein (2014: 42-44), climate change deniers may be getting the scientific facts wrong, yet leading figures of the Heartland Institute very clearly see that the economic and political consequences of climate change are much more threatening to their deepest convictions as they would require profound changes to 
the capitalist system of energy consumption and free market economy as well as a massive increase of government interference in many areas of life.

\subsection{Climate change activist Greta Thunberg}

Despite the ever growing certainty of climate science, climate action has been stalling for the last few years. New impetus, however, has been given to awareness and action regarding climate change by Greta Thunberg and her Fridays for Future movement.

In August 2018, Greta Thunberg started a climate movement with her school strike. She sat in front of the Swedish parliament holding a sign that read "School Strike for Climate". She inspired many youngsters to follow suit and started a worldwide climate movement which culminated in a worldwide strike on 20 September 2019. 'Climate strike' was even declared the word of the year by Collins Dictionary (see Time Magazine 2019) and Greta Thunberg was nominated for the Nobel Peace Prize. Thunberg's uncompromising campaigning for climate action and her mobilisation of young people worldwide has urged politicians around the globe to put climate change/action on the political agenda (again). Greta Thunberg's speeches are characterised by direct messages and simple sentences which convey her very clear message: She communicates her anger at the adults who do not act despite the imminent danger of climate change which threatens the future of the young and even the existence of humankind.

The following extract from Thunberg's speech "Our House is on Fire" at the World Economic Forum (WEF) in Davos, 2019 illustrates her way of communicating (Thunberg 2020):

(6) Our house is on fire, I am here to say our house is on fire. According to the IPCC we are less than 12 years away from not being able to undo our mistakes.

We are facing a disaster of unspoken sufferings for enormous amounts of people and now is not the time for speaking politely, we're focusing on what we can or cannot say. Now it's the time to speak clearly. Solving the client [climate!] crisis is the greatest and most complex challenge that Homo sapiens has have ever faced.

The main solution however is so simple that even a small child can understand it. We have to stop the emissions of greenhouse gases. And either we do that or we don't.

We are now at a time in history where everyone with any insight of the climate crisis that threatens our civilization and the entire biosphere must 
speak out in clear language, no matter how uncomfortable and unprofitable that may be. We must change almost everything in our current societies. [...]

Adults keep saying we owe it to the young people to give them hope. But I don't want your hope, I don't want you to be hopeful. I want you to panic, I want you to feel the fear I feel every day. And then I want you to act, I want you to act as if you would in a crisis. I want you to act as if the house was on fire, because it is.

What is striking in Greta Thunberg's rhetoric is the high level of facticity and directness, a language that is totally devoid of any hedges/mitigation. Climate change is taken as a fact and its existence (and definition as a crisis) is presupposed. She demands that people take action and change, using the inclusive 'we' first but switching to 'you' to address her audience's responsibilities. She only allows the alternatives to 'stop emissions' or 'not to do so' and demands that societies change dramatically. She repeatedly uses the very strong directive form 'I want you to' to emphasize the urgency of the situation and demands people act like they would in a crisis.

Greta Thunberg has started a movement which has given a strong impetus to climate change action at a time when the interest in the topic seemed to be dwindling and economic concerns were foregrounded. Climate change has become a main agenda for politicians in many countries again which they cannot ignore.

\section{Conclusion}

Climate change communication involves numerous groups of actors such as scientists, political decision makers, corporate representatives, media representatives and the general public. Many studies have demonstrated that the strategies for translating scientific results into everyday language have not always proved successful. In particular, the communication and interpretation of uncertainty has turned into a problem. The findings of this study have demonstrated that the IPCC's well-intentioned attempt to use verbal uncertainty expressions has not been successful and may have resulted in a language which is too vague to promote action. As we have seen, the media reports frequently resorted to numerical expressions or combined these with the verbalised forms. In addition, the terms of likelihood applied by the IPCC have turned out to be vulnerable to misuse by the deniers. The study also demonstrates that the climate deniers prefer to use 
certainty expressions with high facticity in their denials, while Greta Thunberg considers climate change as a fact and formulates her view accordingly.

The question of what effective climate change communication requires has been addressed by researchers in media and communication studies (see for example Nerlich et al. 2010); even the IPCC has felt the need to address the discrepancy between science communication and communicating its results to the general public. For this reason guidelines have been provided for IPCC authors when communicating climate change to the general public (Corner et al. 2018). One point deals with communicating uncertainty and is summarised by the authors in the following two sentences:

Uncertainty is a feature of climate science that shouldn't be ignored or sidelined, but can become a major stumbling block in conversations with non-scientists. Focus on the 'knowns' before the 'unknowns' and emphasise where there are areas of strong scientific agreement around a topic (Corner et al. 2018: 5).

This passage is followed by a detailed discussion of the different ways of understanding and focussing of uncertainty in science and in public communication, explaining that uncertainty may be interpreted as ignorance in public understanding. It is also stated that merely focusing on what researchers agree on will not suffice, as deep-rooted beliefs, values and political conviction will not be overcome with facts. Rather, scientists should connect scientific knowledge with stories and people's everyday experience, for example in connection with extreme weather events (Corner et al. 2018: 17-19).

However, the lack of success in promoting climate action cannot only be put down to communication. Our current system has become increasingly averse to citizen engagement and participation in the debate. It has stalled required action in favour of the interests of large corporations. The underlying ideology of growth needs to be questioned as it is the basis of the exploitation of natural resources and growing emissions which are exacerbating the climate crisis.

Potential directions in climate change communication which have surfaced from the discussions in this paper could include the following suggestions:

- Relate to people's local spaces and environments and refer to the damages that climate change has already caused.

- Encourage participation in climate debate and action on the basis of the results provided by climate science.

- Climate communicators, in particular journalists, should not take 'growthism' for granted as the main ideology in order to open up people's perspective on ways of living. 


\section{References}

Alexander, Richard. 2009. Framing discourses on the environment: A critical discourse approach. London: Routledge.

Bailey, Adriana, Lorine Giangola \& Maxwell T. Boykoff. 2014. How grammatical choice shapes media representations of climate (un)certainty. Environmental Communication 8(2). 197-215.

Bolsen, Toby \& Matthew A. Shapiro. 2018. The US news media, polarization on climate change, and pathways to effective communication. Environmental Communication 12(2). 149-163.

Boykoff, Maxwell T. 2007. From convergence to contention: United States mass media representations of anthropogenic climate change science. Transactions of the Institute of British Geographers NS 32. 477-489.

Boykoff, Maxwell T. 2008. The cultural politics of climate change discourse in UK tabloids. Political Geography 27. 549-569.

Carvalho, Anabela, Margit van Wessel \& Pieter Maeseele. 2017. Communication practices and political engagement with climate change: A research agenda. Environmental Communication 11(1). 122-135.

Collins, Luke \& Brigitte Nerlich. 2016. Uncertainty discourses in the context of climate change: A corpus-assisted analysis of UK national newspaper articles. Communications - The European Journal of Communication Research. Special Issue Scientific Uncertainty in Public Discourse 41(3). 291-313.

Corner, Adam, Chris Shaw \& Jamie Clarke. 2018. Principles for effective communication and public engagement on climate change: $A$ handbook for IPCC authors. Oxford: Climate Outreach. https://www.ipcc.ch/site/assets/uploads/2017/08/Climate-OutreachIPCC-communications-handbook.pdf.

Cox, Robert. 2006. Environmental communication and the public sphere. Thousand Oaks: Sage Publications.

Delaney, Kate. 2009. Approaches to uncertain futures. In Gabriele Bammer \& Michael Smithson (eds.), Uncertainty and risk: Multidisciplinary perspectives, 137-155. London: Routledge.

Döring, Martin. 2018. Media reports about natural disasters. In Alwin F. Fill \& Hermine Penz (eds.), The Routledge handbook of ecolinguistics, 293-308. New York: Routledge.

Entman, Robert E. 1993. Framing: Toward clarification of a fractured paradigm. Journal of Communication 43. 51-58.

Etz, Alexander. 2018. Introduction to the concept of likelihood and its applications. Advances in Methods and Practices in Psychological Science 1(1). 60-69.

Fill, Alwin. 1993. Ökolinguistik: Eine Einführung. Tübingen: Gunter Narr Verlag.

Fløttum, Kjersti. 2010. A linguistic and discursive view on climate change discourse ASp [Online], 58. Online since 30 November 2013, connection on 30 April 2019. URL. https://doi.org/10. 4000/asp.1793 http://journals.openedition.org/asp/1793.

Harris, Adam J. L., Adam Corner, Juemin Xu \& Xiufang Du. 2013. Lost in translation? Interpretations of the probability phrases used by the Intergovernmental Panel on Climate Change in China and the UK. Climatic Change 121. 415-442.

Hyland, Ken. 2006. English for academic purposes: An advanced resource book. London: Routledge.

Hulme, Mike. 2018. "Gaps” in climate change knowledge: Do they exist? Can they be filled? Environmental Humanities 10(1). 330-337. 
IPCC. 2014. Report 2014-synthesis report for policy makers. https://www.ipcc.ch/pdf/ assessment-report/ar5/syr/AR5_SYR_FINAL_SPM.pdf.

IPCC. 2018. Summary for policymakers. In V. Masson-Delmotte, P. Zhai, H.-O. Pörtner, D. Roberts, J. Skea, P.R. Shukla, A. Pirani, W. Moufouma-Okia, C. Péan, R. Pidcock, S. Connors, J.B.R. Matthews, Y. Chen, X. Zhou, M.I. Gomis, E. Lonnoy, T. Maycock, M. Tignor \& T. Waterfield (eds.), Global warming of $1.5^{\circ} \mathrm{C}$. An IPCC Special Report on the impacts of global warming of $1.5^{\circ} \mathrm{C}$ above pre-industrial levels and related global greenhouse gas emission pathways, in the context of strengthening the global response to the threat of climate change, sustainable development, and efforts to eradicate poverty. In Press. https://www.ipcc.ch/ sr15/chapter/spm/.

Klein, Naomi. 2014. This changes everything: Capitalism vs. climate. New York: Simon \& Schuster Paperbacks.

Kövesces, Zoltan. 2006. Language, mind and culture: A practical introduction. Oxford: Oxford University Press.

Kuha, Mai. 2009. Uncertainty about causes and effects of global warming in U.S. news coverage before and after Bali. Language and Ecology 2(4). 1-18.

Labinaz, Paolo \& Marina Sbisà. 2014. Certainty and uncertainty in assertive speech acts. In Andrzej Zuczkowski, Ramona Bongelli, Ilaria Riccioni \& Carla Canestrari (eds.), Communicating certainty and uncertainty in medical, supportive and scientific contexts, 31-56. Amsterdam: John Benjamins.

Lakoff, George. 2010. Why it matters how we frame the environment. Environmental Communication 4(1). 70-81.

Machin, David \& Andrea Mayr. 2012. How to do critical discourse analysis: A multimodal introduction. London: Sage.

Mazur, Allan \& Jinling Lee. 1993. Sounding the global alarm: Environmental issues in the US national news. Social Studies of Science 23(4). 681-720.

Mastrandrea, Michael D., Christopher B. Field, Thomas F. Stocker, Ottmar Edenhofer, Kristie L. Ebi, David J. Frame, Hermann Held, Elmar Kriegler, Katharine J. Mach, Patrick R. Matschoss, Gian-Kasper Plattner, Gary W. Yohe \& Francis W. Zwiers. 2010. Guidance note for lead authors of the IPCC fifth assessment report on consistent treatment of uncertainties. Intergovernmental Panel on Climate Change (IPCC). Available at http://www.ipcc.ch.

NASA. 2020. Global climate change. https://climate.nasa.gov/scientific-consensus/ (accessed 20 March 2020).

Nerlich, Brigitte, Nelya Koteyko \& Brian Brown. 2010. Theory and language of climate change communication. Wiley Interdisciplinary Reviews: Climate Change 1(1). 1-17.

NIPCC. 2020. Nongovernmental international panel on climate change. http://climatechangereconsidered.org/ (accessed March 2020).

Painter, James. 2013. Climate change in the media: Reporting risk and uncertainty. London: I.B. Tauris.

Painter, James \& Neil T. Gavin. 2016. Climate skepticism in British newspapers, 2007-2011. Environmental Communication 10(4). 432-452.

Penz, Hermine. 2018. 'Global Warming' or 'Climate Change. In Alwin F. Fill \& Hermine Penz (eds.), The Routledge handbook of ecolinguistics, 277-292. New York: Routledge.

Rachlin, Howard. 1989. Judgment, decision and choice. New York: Freeman.

Sarangi, Srikant. 2002. The language of likelihood in genetic-counseling discourse. Journal of Language and Social Psychology 21(1). 7-31. 
Schäfer, Mike S. \& Inga Schlichting. 2014. Media representations of climate change: A metaanalysis of the research field. Environmental Communication 8(2). 142-160.

Smithson, Michael. 2009. The many faces and masks of uncertainty. In Gabriele Bammer \& Michael Smithson (eds.), Uncertainty and risk: Multidisciplinary perspectives, 13-25. London and Sterling, VA: Routledge.

Steffensen, Sune \& Alwin Fill. 2014. Ecolinguistics: The state of the art and future horizons. Language Sciences 41. 6-25.

Stibbe, Arran. 2014. An ecolinguistic approach to critical discourse studies. Critical Discourse Studies 11(1). 117-128.

Stibbe, Arran. 2015. Ecolinguistics: Language, ecology and the stories we live by. London: Routledge.

Thunberg, Greta. 2020. Speeches. https://www.fridaysforfuture.org/greta-speeches\#greta_ speech_tedx (accessed 26 Feb 2020).

Van der Heijden, Kees. 1996. The art of strategic conversation. Chichester, UK: Wiley and Sons. Van Leeuwen, Theo. 2008. Discourse and practice. Oxford: Oxford University Press.

\section{Bionote}

\section{Hermine Penz}

Institut für Anglistik/Department of English Studies, Karl-Franzens-Universität Graz/University of Graz, Heinrichstrasse 36, A-8010 Graz, Austria

hermine.penz@uni-graz.at

Hermine Penz received both her doctoral and post-doctoral degrees in English linguistics from the University of Graz, Austria and is currently Associate Professor at this university. Her research interests include ecolinguistics and language and culture, with a focus on intercultural communication in English as a lingua franca. She recently co-edited (with Alwin F. Fill) The Routledge Handbook of Ecolinguistics (2017, Routledge). 